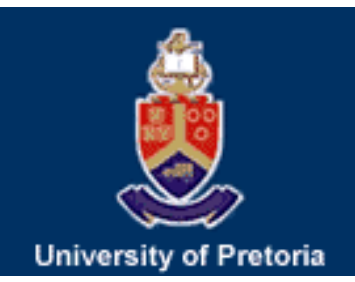

University of Pretoria

Department of Economics Working Paper Series

Parameter Uncertainty and Inflation Dynamics in a Model with Asymmetric Central Bank Preferences

Laban K. Chesang

University of Pretoria

Ruthira Naraidoo

University of Pretoria

Working Paper: 2014-37

August 2014

Department of Economics

University of Pretoria

0002, Pretoria

South Africa

Tel: +27124202413 


\title{
PARAMETER UNCERTAINTY AND INFLATION DYNAMICS IN A MODEL WITH ASYMMETRIC CENTRAL BANK PREFERENCES
}

\section{LABAN K. CHESANG \& RUTHIRA NARAIDOO*}

University of Pretoria, Department of Economics, Pretoria 0002 South Africa

August 2014

\begin{abstract}
This paper exploits the Lucas' (1973) signal extraction model to study the effect of uncertainty in the outputinflation trade-off on inflation, using a monetary model with asymmetric central bank preferences over inflation and output. We show that the implication of the uncertainty is two-fold: firstly, it causes the interaction of output and volatility of monetary policy to influence inflation movements so that, higher volatility in monetary policy causes inflation to rise. Secondly, as suggested in an optimal rule, it causes output to contract by less whenever inflation increases above the target, and to expand by less whenever inflation is below the target. We also find that the Reserve Bank's asymmetric aversion to inflation stabilization explains inflation movements significantly, and that the monetary authority seems to penalize more for inflationary rather than deflationary pressures. Overall, the Bank's deflationary bias would allow for a relatively flat output-inflation trade-off, which could be helpful for economic stability.
\end{abstract}

JEL Classification codes: E31; E52; E58; E61

Keywords: monetary policy, asymmetric preferences, Inflation, Uncertainty

\footnotetext{
*Laban K. Chesang, Email claban_2010@yahoo.com. Ruthira Naraidoo , Faculty of Economics and Management Sciences, Department of Economics, University of Pretoria, Pretoria 0002, South Africa, E-mail: ruthira.naraidoo@up.ac.za
} 


\section{Introduction}

Since the year 2000, the South African Reserve Bank (SARB) has remained committed to inflation targeting as the anchor of monetary policy with the aim of achieving long term price stability. Indeed, most economists hold the view that monetary policy has real effects on the economy in the short run, but in the long run, the effects fall entirely on prices. As such, the central bank plays a critical role in determining the path of inflation (and output) in the economy. The possibility that monetary policy may induce an inflationary bias, as first suggested by Barro and Gordon (1983), has been investigated in a number of empirical studies including Ruge-Murcia (2003, 2004), Sweidan (2009) and Doyle and Falk (2010), among others. Their results vary. Our paper uses a similar framework used in these studies to consider the role of uncertainty about the output-inflation trade-off in interpreting the inflation rate. We hypothesize that the more uncertain is monetary policy, the more steeper is the Phillips curve; in turn, the higher is the rate of inflation.

We focus on an asymmetric preference model for the central banker, although we initially start with quadratic preferences. A huge body of empirical work on monetary policy reaction functions and estimation of central bank preference parameters offer evidence supporting asymmetries in either inflation or output gap in the central bank loss function (see e.g., Nobay and Peel (2003), Ruge-Murcia (2003, 2004) and Surico (2007)) for evidence from developed countries, and Naraidoo and Raputsoane (2011) and Kasaï and Naraidoo (2012) for evidence from South Africa). Empirical contributions such as Sweidan (2009) and Doyle and Falk (2010) have shown that when central bank preferences are asymmetric, policymakers care about the sign as well as the extent of the deviations of output and inflation from target. Monetary policy in this case suffers from time inconsistency problem, thus allowing for the variance (uncertainty) of both inflation and output to influence the equilibrium rate of inflation. If for instance the central bank dislikes high inflation more than she dislikes low inflation, then an increase in the volatility of inflation is likely to lead to a lower average inflation i.e. the central bank would likely reduce the average inflation rate so as to insulate against high inflation shocks. In view of

this, it can be argued that uncertainty (which, partly may be attributed to asymmetric preferences) is often recognized as an integral part in monetary policy decision making.

The relevant literature for our work dwell on the Barro and Gordon (1983) inflationary bias hypothesis. Ruge-Murcia (2003) for instance shows that the central banks' preferences significantly explain inflation rates for Canada, Sweden and the UK, and that inflation has generally been below target. Ruge-Murcia (2004) provides evidence in support of the proposition that an inflation (or a deflation) bias is proportional to the conditional variance of unemployment for the G7 countries. Moreover, the overall results are consistent with the 
view that positive unemployment deviations from the target are weighed more severely than negative ones in the loss function. His study was motivated by Cukierman (2000) who first showed that two conditions should be satisfied for an inflation bias to arise when the central bankers target the natural rate of unemployment, i.e. (i) uncertainty about next period's realizations of inflation and unemployment, and (ii) asymmetric unemployment preference. Cassou et al. (2012) find similar results as Ruge-Murcia (2003, 2004). They show that the monetary authority targets permanent output rather than some higher level of output which would be required in a BarroGordon type model.

Although Surico (2007) does not explicitly investigate the role of variances of inflation and output, he examines the possible effect of changes in the degree of asymmetry in preferences, and finds that such changes seem to account for a sizable fraction of the historical decline in US inflation. Sweidan (2009) finds that the variances of both output and inflation influenced Jordanian inflation rates over the period1992-2007 and that Jordanian central bank preferred higher inflation and higher level of output. In a related study, Doyle and Falk (2010) observe that previous studies suffer from a spurious regression problem, and thus control for this problem by estimating their model as a cointegration relationship. Their results do not support the view that volatility of unemployment does explain inflation trends, except in only three out of the sample of thirteen countries. However, they find a significant relationship between inflation and its own volatility in more than half of the countries.

The literature reviewed above has often assumed an observable state of the economy. In this paper however, we go further and examine how, in a similar framework uncertainty about the output-inflation tradeoff may be useful in interpreting inflation dynamics. The literature on parameter uncertainty and monetary policy is grounded on Brainard's (1967) attenuation principle, which hypothesizes that uncertainty dampens the monetary authorities' response to target variables of monetary policy relative to when monetary policy decisions are made under complete certainty. Numerous empirical studies including Wieland (2000), Orphanides et al. (2000) and Svensson and Williams (2008) present evidence in support of Brainard's result. On the contrary Giannoni (2002), Söderström (2002), Kimura and Kurozumi (2007) and Tillman (2011) present evidence in support of an aggressive reaction of monetary policy under uncertainty ${ }^{1}$. According to Söderström (2002) for instance, in the face of uncertain inflation dynamics, the monetary authority faces even greater degree of uncertainty about the state economy so that the rate of inflation drifts even farther from target. To reduce the

\footnotetext{
${ }^{1}$ Most of these studies employ robust control problem solving techniques, and have shown that under parameter uncertainty robust optimal Taylor rules prescribe in general a stronger monetary policy response to fluctuations in inflation and output gap.
} 
amount of uncertainty about the future path of inflation, optimal policy becomes more aggressive, pushing inflation closer to target. In a related study, Peel (2001) demonstrates that expected inflation (and hence actual inflation) is higher when the weight on inflation stabilization is uncertain, and it is lower when the weight on output stabilization is uncertain.

The contribution of our paper is to examine the implication of parameter uncertainty for the behaviour of inflation when central bank preferences are asymmetric. Specifically, our modelling approach takes into account uncertainty about the slope of the Phillips curve, which we show, varies inversely with monetary policy shock. In the New Keynesian type models, this parameter appears in the targeting rule describing optimal monetary policy, and hence is expected to affect optimal dynamics in the model. Empirical evidence on the effect of central bank preferences and changing volatility on inflation trends is limited and virtually inexistent in sub Saharan Africa in particular. What we do in this paper is to derive analytically the optimum process for inflation facing the policymaker, and then take the model to the data, taking particular interest of the role of the variance of inflation and output as well as parameter uncertainty in interpreting inflation.

The results show that the effect of uncertainty about the output-inflation trade-off is to cause the interaction of output gap and volatility of monetary policy to influence inflation dynamics. As suggested in an optimal rule, this additional determinant causes output to decrease by less whenever inflation is above the target i.e., monetary authority increases the nominal interest rate by less, than under certainty equivalence. Furthermore, given the level of the gap in output, the effect of positive monetary policy shock is to causes the rate of inflation to rise, since the economy's aggregate supply curve steepens as a result. The other key results indicate that central bank's asymmetric aversion to inflation plays an important role in interpreting the inflation rate. Moreover, the Reserve bank seems to dislike high inflation more than she dislikes low inflation rate, i.e., she has deflationary bias. We further find that the model with asymmetric preferences yields relatively smaller coefficients relative to the one under quadratic preferences. This would suggest that, since the monetary authority places more weight on positive deviation of inflation from target, inflation movements over the sample period considered are restrained, on average.

The remainder of the paper is organized as follows. Section II presents the model and solves for the reduced form process for inflation. Section III describes the data and estimation technique, and discusses the results. Section IV draws some conclusions.

\section{The Model}




\section{A. Structure of the economy}

The model starts with the common short run aggregate supply curve ${ }^{2}$, which is motivated by classical contributions of Friedman (1968) and Lucas (1973). It is given by

$$
Y_{t}=Y_{t}^{N}+\theta\left(P_{t}-P_{t}^{e}\right)+u_{t}, \quad \theta>0
$$

where $Y_{t}$ is the real (observed) output, $Y_{t}^{N}$ denotes the natural or potential output at time $t, P_{t}$ is the price level at time $t, P_{t}^{e}$ is the expected price level at time $t$ given information at time $t-1$. The parameter $\theta$ indicates by how much output responds to unexpected changes in the price level. $u_{t}$ is a supply shock that is required to generate a short-run trade-off between inflation and output stabilization. The basis of the Lucas supply curve in (1) above is that firms observe the price of their own product and not the aggregate price. As a result of this imperfect information, they sometimes confuse aggregate price increase (say, when the policymaker raises money supply, to which they should not respond) with relative price increase (to which they should respond by increasing output). Equation (1) says that output rises above its natural level when the price level is higher than expected. According to Lucas (1973) the positive slope of the aggregate supply curve (1/ $\theta)$ depends on the volatility of aggregate demand ${ }^{3}$.

In order to take into account changes in the output-inflation trade-off over time, and introduce parameter uncertainty about the slope of the aggregate supply equation (1) above, we make use of Lucas' (1973) signal extraction model, in which firms are unable to distinguish between aggregate and relative price shocks. While these shocks are not directly observable, their magnitude must be inferred from the behaviour of individual firm prices. In appendix A, we show that the aggregate supply curve under incomplete information (uncertainty) can be written as

$$
Y_{t}=Y_{t}^{N}+\kappa_{t}\left(P_{t}-P_{t}^{e}\right)+u_{t}
$$

where $\kappa_{t}=\frac{\theta \sigma_{z t}^{2}}{\sigma_{z t}^{2}+\sigma_{\varepsilon t}^{2}}$ from which $\sigma_{z t}^{2}$ and $\sigma_{\varepsilon t}^{2}$ respectively are variances of relative price and aggregate price shocks. The signal extraction model suggests that the slope of the Phillips curve depends on the behaviour

\footnotetext{
${ }^{2}$ A huge body of empirical work (including, among others Ruge-Murcia (2003, 2004), Surico (2008), Sweidan (2009), Doyle and Falk (2010) and Cassou et al. (2012) apply this framework.

${ }^{3}$ Specifically, when aggregate demand fluctuates, aggregate prices fluctuate too, and since most price changes do not represent changes in relative prices, producers should have learned not to respond much to unexpected price movements. In this case, the aggregate supply curve becomes relatively steep ( $\boldsymbol{\theta}$ will be small). On the contrary, when aggregate demand is relatively stable, producers should have learned that most price changes they observe are relative price changes, and should therefore respond to unanticipated price movements. In this case, the aggregate supply curve becomes relatively flat ( $\theta$ will be large).
} 
of the relative and aggregate price shocks. The assumption here is that firms know the variances of the shocks, and use that information to decide on their production plans. In particular, at any given time period $t$, if firms know that aggregate prices are much more volatile than relative prices, they ascribe most of the current movements in prices they observe to an aggregate shock. In that case, since $\sigma_{\varepsilon t}^{2}$ will be large relative to $\sigma_{z t}^{2}$ as $\kappa_{t}$ becomes smaller, the slope of the Phillips curve becomes steeper. Firms will then not alter their production levels. In the limit, when $\sigma_{z t}^{2} \rightarrow 0 \Rightarrow \kappa_{t} \rightarrow 0$, relative price changes are virtually certain to reflect aggregate price changes, the supply curve is nearly vertical. In other words they infer that all local prices have shifted identically: as such there is no reason to raise output. In contrast, if firms know that relative prices are much more volatile than aggregate prices, they interpret local price movements as predominantly relative price movements. In this case $\sigma_{\varepsilon t}^{2}$ will be small relative to $\sigma_{z t}^{2}$, and firms will alter their production levels. The Phillips curve will be flatter. In the limit, as $\sigma_{\varepsilon t}^{2} \rightarrow 0$ when prices are generally small, the slope of the Phillips curve $\kappa_{t}$ approaches its limiting value of $\theta$.

In a large cross-country sample of Phillips curves, Lucas (1973) finds that countries with monetary (price) stability have flatter Phillips curves; and many more subsequent studies have confirmed this evidence. Recent empirical studies (e.g., Roberts (2006), De Veirman (2007) and Ball and Mazumder, (2011)) find evidence of declining output-inflation trade-off over time. The Lucas hypothesis implies that periods of lower aggregate demand fluctuations are associated with large effects on a representative firm's production, and hence aggregate output. This in turn has a smaller impact on inflation, implying a flatter aggregate supply curve. Conversely, periods of high volatility in aggregate demand implies a steeper curve. In the light of this, letting the variances of the shocks defining $\kappa_{t}$ in equation (2) be time dependent is crucial in generating a time varying output-inflation trade-off.

By adding and subtracting $P_{t-1}$ on the terms inside the brackets in the right hand side of equation (2) we have an expectations-augmented Phillips curve that describes private sector behaviour as,

$y_{t}=\kappa_{t}\left(\pi_{t}-\pi_{t}^{e}\right)+u_{t}$

where $y_{t}=Y_{t}-Y_{t}^{N}, \pi_{t}=P_{t}-P_{t-1}$ and $\pi_{t}^{e}=P_{t}^{e}-P_{t-1}$. Ignoring the time subscript on the slope term, equation (3) can be re-written as one resembling the New Keynesian Phillips curve in Woodford (1999) and 
McCallum and Nelson (2000) among others, i.e $\pi_{t}=\pi_{t}^{e}+(1 / \kappa) y_{t}-(1 / \kappa) u_{t}$ with $\pi_{t}^{e}$ defined as $E_{t} \pi_{t+1}$. As Surico (2008) notes, this alternative specification of $\pi_{t}^{e}$ does not affect the derivation of optimal monetary policy under discretion or commitment. From (3), a decrease in slope (a smaller $1 / \kappa_{t}$ ) implies that firms adjust prices less frequently, which in turn implies a flatter Phillips curve. In turn, the monetary authority faces a more favourable short-term output-inflation trade-off, and would likely pursue an expansionary policy that boosts output. Changes in monetary policy too, have implications for the slope of the Phillips curve. Specifically, a policy associated with low and stable inflation is likely to lead to less-frequent price adjustment and therefore a reduction in the slope of the Phillips curve. Rudebusch (2005) and Roberts (2006) support this argument.

The main empirical implication of the signal extraction model is that the slope of the aggregate supply curve, $\kappa_{t}$ is inversely related to the variability (i.e. uncertainty) of an aggregate nominal disturbances (see e.g., Lucas (1973), Barro (1977), Minford and Peel (2002) and Apergis and Miller (2004)). We therefore utilize equation (A18), and treat $\sigma_{\varepsilon t}^{2}$ as the measure of nominal (or aggregate demand) disturbance and henceforth labelled as $\sigma_{m t}^{2}$, and further let the variance of the relative price shock, $\sigma_{z t}^{2}$ be constant, that is $\sigma_{z}^{2}$. We can then specify the linear relationship in (A18) as

$$
\kappa_{t}=\nu_{0}+\nu_{1} \sigma_{m t}^{2}
$$

where $v_{0}$ (which includes $\sigma_{z}^{2}$ ) and $v_{1}$ are constants, as defined in equation (A16). From the definition of $\kappa_{t}$ in (2) $v_{0}>0$ can be interpreted as the average slope of the Phillips curve. It also follows that $v_{1}<0$. More specifically, as $\sigma_{m t}^{2}$ rises, firms misperceive a smaller portion of any change in overall price level as a change in relative price, so that, any given change in aggregate demand will affect inflation more than it affects output. Consequently, the Phillips curve becomes steeper (i.e. $1 / \theta$ in equation (1) increases). Conversely, as $\sigma_{m t}^{2}$ decreases, a larger fraction of any change in the overall price level is misperceived by firms as being a change in the relative price. In this case, a given change in aggregate demand will have a larger impact on firms' output, and a smaller effect on inflation i.e. the Phillips curve becomes relatively flat.

Empirically, although Lucas (1973), and subsequent other studies, including more recently, Abbott and Martínez (2008) uses innovations in nominal GNP (or GDP) as a measure of $\sigma_{m t}^{2}$, he proposes the use of any of the demand-shift variables, notably: monetary and fiscal policies and variations in export demand. Most studies 
use innovations in monetary policy measured as unanticipated money supply (see e.g., Barro 1977), Kormendi and Meguire (1991), Apergis and Miller (2004)) while Glick and Hutchison (1990) use both unanticipated fiscal and monetary policy shocks as instruments. Motivated by this literature, in our empirical analysis we use innovations in monetary policy derived from (nominal) money supply process ${ }^{4}$ as a proxy for $\sigma_{m t}^{2}$. Since there is no standard model describing the evolution of money in the literature, we use the money supply process, as in Kormendi and Meguire (1991) and assume that forecasts of changes in money supply can be approximated by variants of the following process:

$D M_{t}=\hat{\tau}_{0}+\hat{\tau}_{1} D M_{t-1}+\hat{\tau}_{2} D M_{t-2}+\hat{\tau}_{3} t+\varepsilon_{t}^{m}$

where $D M_{t}$ is the first difference of the natural logarithm of nominal money stock, $\tau$ 's are estimated parameters, $t$ it time trend while $\varepsilon_{t}^{m}$ is white noise. The residuals from the equation would provide a measure of unanticipated nominal monetary policy shock $\left(\sigma_{m t}^{2}\right)$.

\section{B. The central bank's objective function}

Our task is to use the standard monetary model to reformulate and solve the central bank's optimization problem under discretion taking into account the uncertainty of the slope of the Phillips curve. The widely used specification for central bank preferences is the quadratic loss function. However recent literature suggests the use of asymmetric (LINEX) preferences, whereby the central bank is allowed, but not required, to treat differently positive and negative deviations of inflation and output from the targets. This, according to Orphanides and Wilcox (2002) can arise from the fact that, the policymaker who is endowed with inflation and output stabilization, tend to focus on stabilizing output when inflation is low, but on fighting inflation when inflation is high. The LINEX loss function can be written as follows:

$L_{t}=\left(\frac{e^{\alpha \pi_{t}}-\alpha \pi_{t}-1}{\alpha^{2}}\right)+\lambda\left(\frac{e^{y_{t}}-\gamma_{t}-1}{\gamma^{2}}\right) \alpha \neq 0, \gamma \neq 0$

$\alpha$ and $\gamma$ capture the degree of asymmetry in the objective function of the central bank ${ }^{5}$, while $\lambda$ measures the relative weight placed on output deviations. The asymmetric loss function we use in this paper is motivated by

\footnotetext{
${ }^{4}$ In appendix B, we show that in the Lucas' misperception model, surprises in aggregate prices can only come from surprises in money.

${ }^{5}$ Employing L'Hopital's rule on equation (6) we find that as $\alpha \rightarrow 0$ (and $\gamma \rightarrow 0$ ) the loss function reduces to the quadratic specification. This result suggests that the hypothesis that central bank's preferences are quadratic over inflation (and output) could be tested econometrically by evaluating whether $\alpha$ (and $\gamma$ ) is significantly different from zero.
} 
empirical evidence showing that SARB's response to inflation and output deviations is asymmetric (see e.g., Naraidoo and Raputsoane (2011) and Kasaï and Naraidoo (2012)). Asymmetries in the loss function mean that the policymaker dislikes deviations from target with one sign more than deviations from target with the other sign. If $\alpha>0$ (implying that the central bank is more concerned about overshooting the target rather than undershooting it) it means that, everything being equal, an increase in inflation relative to the target is weighted more severely than a decrease in inflation of the same magnitude. In fact, from equation (6), we see that whenever inflation is above the target $\left(\pi_{t}>0\right)$ the exponential component of the loss function dominates the linear component, and the loss associated with a positive deviation rises exponentially. So, to the extent that the central bank dislikes high inflation more than she dislikes low inflation, an increase in the volatility of inflation is more likely to lead to lower average inflation. The opposite is true whenever inflation is below the target $\left(\pi_{t}<0\right)$. If $\gamma>0$ the central bank dislikes high output more than she dislikes low output. If $\gamma<0$ the central bank dislikes low output more she dislikes high output.

In what follows, we present the optimal choice of $\pi_{t}$ for the central bank given that the objective is to minimize the central bank loss function subject to the constraint given by the Phillips curve (3). To facilitate comparison of results from alternative specifications of central bank preferences, we first analyze the case of quadratic preferences in sub-section $\mathrm{C}$. We then consider, in sub-section $\mathrm{D}$ the case in which central bank preferences are asymmetric to inflation deviation from target but symmetric to output deviations from potential i.e. specifying (6) as $\gamma$ approach zero. Finally in sub-section $\mathrm{E}$ we analyze the model with asymmetric preferences to both inflation and output gap deviations from target levels i.e. specification (6).

\section{Case 1: Optimum inflation behaviour under quadratic preferences}

In each period the policymaker chooses $y_{t}$ and $\pi_{t}$ so as to minimize its losses subject to the constraint in (3).

By introducing the Lagrange multiplier $\mu_{1 t}$ the policymaker's optimization problem is set up as follows, with output as the indirect control variable and inflation as the state variable

$$
\max _{y_{t}, \pi_{t}} L=E_{t-1}\left[\sum_{t=0}^{\infty}\left\{-\frac{\beta^{t}}{2}\left[\left(\pi_{t}\right)^{2}+\lambda\left(y_{t}\right)^{2}\right]-\beta^{t} \mu_{1 t}\left[y_{t}-\kappa_{t}\left(\pi_{t}-\pi_{t}^{e}\right)-u_{t}\right]\right\}\right]
$$

Taking the first-order conditions with respect to $y_{t}$ and $\pi_{t}$, and eliminating the Langrange multiplier, we have the following targeting rule 


$$
y_{t}=-\frac{1}{\lambda \kappa_{t}} \pi_{t}
$$

which shows the trade-off between inflation and output gap that exists under optimal conditions. It implies that the monetary authority pursues a "lean against the wind" monetary policy, where she contracts aggregate demand below capacity (by raising interest rate) whenever inflation is above the target, and expand it whenever inflation is below target. The implicit solution for inflation from (8) above depends on the parameter defining the slope of the Phillips curve, $\kappa_{t}$ which is time-varying. By using (4) to re-write the time-varying parameter in (8) above, we now have the solution for inflation under uncertainty, as follows

$$
\pi_{t}=-\lambda v_{0} y_{t}-\lambda v_{1} y_{t} \sigma_{m t}^{2}
$$

By re-writing (9) compactly as

$$
\pi_{t}=\rho_{1} y_{t}+\rho_{2} y_{t} \sigma_{m t}^{2}
$$

where $\rho_{1}=-\lambda v_{0}$ and $\rho_{2}=-\lambda v_{1}$ are convolutions of parameters of the model. $v_{0}$ is a constant (which includes $\sigma_{z}^{2}$, and interpreted as the 'average' slope of the Phillips curve), $v_{1}=-\frac{\sigma_{\varepsilon 0}^{2}}{\sigma_{z 0}^{2}+\sigma_{\varepsilon 0}^{2}}$ (see equation A16) and $\lambda$ is the relative weight on output deviations (which is positive). This implies that, since $v_{0}>0$ and $v_{1}<0$, then $\rho_{1}<0$ while $\rho_{2}>0$. Equation (9) shows that when the policymaker's preferences are symmetric over inflation and output, and is uncertain about the inflation-output trade-off, the optimal behaviour of inflation will depend not only to the level of output gap but also to the product (interaction) of output and volatility of the monetary policy. Compared to the case of certainty equivalence in equation (8), equation (9) as an optimal targeting rule implies that the central banker will contract aggregate demand by less (by raising interest rate by less) whenever inflation is above the target, and expand it by less whenever inflation is below the target. To see this, if we compare the impact of an change in output gap on inflation under certainty (i.e. $\partial \pi_{t} / \partial y_{t}=-\lambda v_{0}$ in equation (8)) and uncertainty (i.e. $\partial \pi_{t} / \partial y_{t}=-\lambda v_{0}-\lambda \nu_{1} \sigma_{m t}^{2}$ in equation (9)), one observes that the additional (positive) term in (9) implies that inflation will fall by less in response to a positive gap in output. In other words, uncertainty about the output-inflation trade-off induces a more lenient approach to reducing inflation on the part of the monetary authority. Finally, for a unit change in output gap, the effect of a positive unanticipated money supply shock $\left(\sigma_{m t}^{2}\right)$, is to cause inflation to rise (since $\rho_{2}>0$ ). This borrows 
from the implications of Lucas supply model i.e. with a positive aggregate demand shock, producers will have learnt that the current movement in prices they observe are largely monetary in origin: the aggregate supply curve becomes steeper, implying a larger impact will fall on inflation and a smaller impact on output.

\section{Case 2: Optimum inflation behaviour under asymmetric preferences to inflation}

When the central bank preferences are asymmetric to inflation deviation from target, but symmetric to output fluctuations from potential the policymaker's optimization problem is set up as follows

$$
\max _{y_{t}, \pi_{t}} L=E_{t-1}\left[\sum_{t=0}^{\infty}\left\{-\beta^{t}\left[\left(\frac{e^{\alpha \pi_{t}}-\alpha \pi_{\tau}-1}{\alpha^{2}}\right)+\frac{\lambda}{2}\left(y_{t}\right)^{2}\right]-\beta^{t} \mu_{2 t}\left[y_{t}-\kappa_{t}\left(\pi_{t}-\pi_{t}^{e}\right)-u_{t}\right]\right\}\right]
$$

The first-order conditions yield a potentially nonlinear targeting rule

$$
-E_{t-1}\left(\frac{e^{\alpha \pi_{t}}-1}{\alpha}\right)-\lambda E_{t-1} \kappa_{t} y_{t}=0
$$

which nests the linear form as in (8), as a special case when $\alpha \rightarrow 0$. The targeting rule implies that whenever inflation deviates from target, the policymaker adjusts output (through the interest rate, potentially nonlinearly).

The parameters $\alpha, \lambda, \kappa_{t}$ (which is time varying) and the exponential function govern the asymmetric response of output gap (via interest rate) to the positive and negative deviations of inflation from the target.. Equation (12) can be linearized by transforming the exponential terms by means of a first-order Taylor series expansion around $\alpha=0$ to give

$-E_{t-1} \pi_{t}-\frac{\alpha}{2} E_{t-1}\left(\pi_{t}\right)^{2}-\lambda E_{t-1} \kappa_{t} y_{t}=0$

and assuming that $\pi_{t}$ is conditionally normal, the expression can be approximated for expected inflation and expected output level so that, the deviation of inflation from the target will be a function of output gap as well as the conditional variance of inflation i.e.,

$$
\pi_{t}=-\left(\lambda \kappa_{t}\right) y_{t}-\frac{\alpha}{2} \sigma_{\pi t}^{2}
$$

where $\sigma_{\pi t}^{2}$ is the conditional variance of inflation. Since the conditional variance of inflation is not directly observable, it is possible to construct its estimate on the basis of a full parametric model like an ARCH or GARCH specification of Engle (1982) and Bollerslev (1986). Generated regressors such as $\sigma_{\pi t}^{2}$ in our case can 
be problematic because they measure with noise the true, but unobserved regressor. A standard misspecification test (LM test) for ARCH models would then be applied to assess whether the chosen ARCH model is valid. Equation (14) indicates that, if the central bank dislikes high inflation more than she dislikes low inflation ( $\alpha>0$ ), she would be willing to accept an inflation rate that is lower than the target level, on average. In this case, an increase in the volatility of inflation will cause the policymaker to lower the average inflation rate.

\section{Optimal behaviour of inflation under parameter uncertainty}

We can now consider the implication of time variation in $\kappa$ for inflation dynamics by using (4) to re-write the time-varying coefficient in (14) i.e.

$$
\pi_{t}=-\lambda v_{0} y_{t}-\lambda v_{1} y_{t} \sigma_{m t}^{2}-\frac{\alpha}{2} \sigma_{\pi t}^{2}
$$

which can be re-written compactly as

$$
\pi_{t}=\rho_{1} y_{t}+\rho_{2} y_{t} \sigma_{m t}^{2}+\rho_{3} \sigma_{\pi t}^{2}
$$

where $\rho_{1}=-\lambda v_{0}, \rho_{2}=-\lambda v_{1}$ and $\rho_{3}=-\alpha / 2$, and given that $v_{0}>0, v_{1}<0$ and if $\alpha>0$, then it is expected that $\rho_{1}<0, \rho_{2}>0$ while $\rho_{3}<0$. Equation (16) shows that when the policymaker's preferences are asymmetric over inflation, and is uncertain about the inflation-output trade-off, inflation will respond to the level of output gap, inflation volatility and the product (interaction) of output gap and volatility of money. The interpretation of the first two terms of equation (16) is similar to that we made under quadratic preferences in equation (10) i.e., the effect of uncertainty about the output-inflation trade-off is to cause the monetary authority to reduce output by less (by raising interest rate by less) whenever inflation is above the target, and expand output by less whenever inflation is below the target. The additional variable $\left(\sigma_{\pi t}^{2}\right)$ in (16) implies that since $\rho_{3}<0$, an increase in the volatility of inflation causes the monetary authority to lower the rate of inflation because she dislikes positive deviation of inflation from target more than she dislikes negative deviations. It is worth noting from (16) that while the volatility in monetary policy $\sigma_{m t}^{2}$, causes inflation to rise (due to the steepening of the Phillips curve), volatility in inflation $\sigma_{\pi t}^{2}$, (a supply-side shock) lowers it when the central banker has a deflationary bias. The reason for the latter is that, the bias (due to the central banks increased attempts to stabilize inflation - relative to output) will cause the unconditional expected rate of inflation to fall. 


\section{E. Case 3: Optimum inflation behaviour under asymmetric preferences to both inflation and output gap}

In solving the policymaker's problem when preferences are asymmetric to both inflation and output deviations from target, we set up the optimizing problem as follows

$$
\max _{y_{t}, \pi_{t}} L=E_{t-1}\left[\sum_{t=0}^{\infty}\left\{-\beta^{t}\left[\left(\frac{e^{\alpha \pi_{t}}-\alpha \pi_{\tau}-1}{\alpha^{2}}\right)+\lambda\left(\frac{e^{\aleph_{t}}-\mathcal{Y}_{t}-1}{\gamma^{2}}\right)\right]-\beta^{t} \mu_{3 t}\left[y_{t}-\kappa_{t}\left(\pi_{t}-\pi_{t}^{e}\right)-u_{t}\right]\right\}\right]
$$

Like before, we drive a targeting rule analogous to (12) as

$$
-E_{t-1}\left(\frac{e^{\alpha \pi_{t}}-1}{\alpha}\right)-\lambda E_{t-1} \kappa_{t}\left(\frac{e^{y_{t}}-1}{\gamma}\right)=0
$$

Equation (18) implicitly describes a general optimal targeting rule according to which the policymaker moves the indirect control (via policy rate), potentially nonlinearly, in response to deviations of inflation from target. By linearizing the exponential terms by means of a first-order Taylor series expansion around $\alpha=\gamma=0$, we have

$$
-E_{t-1} \pi_{t}-\frac{\alpha}{2} E_{t-1}\left(\pi_{t}\right)^{2}-\lambda E_{t-1} \kappa_{t} y_{t}-\frac{\lambda \gamma}{2} E_{t-1} \kappa_{t}\left(y_{t}\right)^{2}=0
$$

which can then be approximated for the expected inflation and expected output level, by assuming that each of $\pi_{t}$ and $y_{t}$ is conditionally normal i.e.

$\pi_{t}=-\left(\lambda \kappa_{t}\right) y_{t}-\frac{\alpha}{2} \sigma_{\pi t}^{2}-\frac{\lambda \gamma \kappa_{t}}{2} \sigma_{y t}^{2}$

where $\sigma_{\pi t}^{2}$ and $\sigma_{y t}^{2}$ are, respectively, the conditional variance of inflation and conditional variance of output.

Like $\sigma_{\pi t}^{2}$, an ARCH-type model can be used to construct an estimate of $\sigma_{y t}^{2}$. Equation (20) says that when the policymaker's loss function is asymmetric over both inflation and output, then inflation deviation from the target will be a function of the output gap, the conditional variance of inflation and the conditional variance of output $^{6}$. As alluded earlier if $\alpha>0$, then an increase in the volatility of inflation will cause the policymaker to lower the average inflation rate. In the same way, if the central bank dislikes high output more than she dislikes low output $(\gamma>0)$, then she would be willing to accept an output level that is below the potential level on

\footnotetext{
${ }^{6}$ We showed in section II that when the loss function is quadratic, certainty equivalence holds. The solution in that case implies that
} inflation deviation from target depends only on the first (conditional) moment of output. 
average. In this case, an increase in the volatility of output will cause the policymaker to pursue a contractionary monetary policy (which lowers the rate of inflation). It should be noted that while these sign predictions ( $\alpha>0, \gamma>0$ ) seem plausible for our study, $\alpha<0$ and $\gamma<0$ are theoretically possible under asymmetric preferences loss functions. Surico (2007) points out that $\alpha<0$ would correspond to a situation in which the risk of deflation outweighs the risk of inflation.

\section{Optimal inflation behaviour under parameter uncertainty}

In order to consider the implication of time variation in $\kappa$ for inflation dynamics, we can use (4) to re-write the time-varying coefficients in (20), so that we have a model describing the optimal inflation behaviour that takes into account the unobservable state of the economy i.e.

$\pi_{t}=-\left(\lambda \nu_{0}\right) y_{t}-\left(\lambda v_{1}\right) y_{t} \sigma_{m t}^{2}-\frac{\alpha}{2} \sigma_{\pi t}^{2}-\frac{\lambda \gamma \nu_{0}}{2} \sigma_{y t}^{2}-\frac{\lambda \gamma \nu_{1}}{2} \sigma_{m t}^{2} \sigma_{y t}^{2}$

which can be re-written compactly as

$\pi_{t}=\rho_{1} y_{t}+\rho_{2} y_{t} \sigma_{m t}^{2}+\rho_{3} \sigma_{\pi t}^{2}+\rho_{4} \sigma_{y t}^{2}+\rho_{5} \sigma_{m t}^{2} \sigma_{y t}^{2}$

where $\rho_{1}=-\lambda v_{0}, \rho_{2}=-\lambda v_{1}, \rho_{3}=-\alpha / 2, \rho_{4}=\left(-\lambda \gamma v_{0}\right) / 2$ and $\rho_{5}=\left(-\lambda \gamma v_{1}\right) / 2$. Given that $v_{0}>0, v_{1}<0, \alpha>0$ and $\gamma>0$ then individually, $\rho_{1}<0, \rho_{2}>0, \rho_{3}<0, \rho_{4}<0$ and $\rho_{5}>0$ would be theoretically plausible. By comparing equation (21) with equation (21), without time subscripts on the parameters in (21), we see that whereas asymmetric preferences $\alpha$ and $\gamma$ independently introduce volatility in inflation and output gap into the inflation equation, uncertainty about the slope of the Phillips curve adds two interaction terms; one consisting output gap and volatility of monetary policy, and the other comprising the volatilities of monetary policy and output gap. For these two terms, a higher unanticipated money supply shock causes a steeper output-inflation trade-off in the economy's aggregate supply curve, implying that a larger (positive) impact will fall on inflation (thus, $\rho_{2}>0, \rho_{5}<0$ ).

\section{Empirical Estimation}

\section{A. Data description and estimation}

The empirical analysis is carried out using monthly seasonally adjusted observations of inflation (measured by the annual change in the consumer price index), output gap (measured as the log-deviation of coincidental 
business cycle indicator from a Hodrick-Prescott (1997) trend) and nominal money stock (measured by broad money supply - M3) ${ }^{7}$. Data on business cycle indicator and money supply is sourced from SARB's monthly data releases, while that on inflation is obtained from the International Monetary Fund's International Financial Statistics (IFS). We work with stationary series.

In models in which a conditional variance is one of the explanatory variables, such as ours, estimates can be biased and inconsistent if the ARCH-type model used is misspecified. Therefore, an LM test for neglected ARCH effects is applied to the standardized residuals from the three equations (of inflation, money and output). The ARCH-LM test is used to test the null hypothesis of conditional homoskedasticity. Upon rejecting the null hypothesis, the three equations are consequently re-estimated (more efficiently) allowing for $\mathrm{ARCH}$ effects in the residuals using the $\mathrm{GARCH}(1,1)$ model with the variance equations defined as

$$
\sigma_{i, t}^{2}=k_{0 i}+k_{1 i} u_{i, t-1}^{2}+k_{2 i} \sigma_{i, t-1}^{2}
$$

for $i=\pi, m, y . k_{0 i}, k_{1 i}$ and $k_{2 i}$ are parameters while $\sigma_{\pi t}^{2}, \sigma_{m t}^{2}$ and $\sigma_{y t}^{2}$ are, respectively, the conditional variance of inflation, conditional variance of money supply and conditional variance of output. Equation (23) implies that the conditional variances depend on the long term variance $k_{0 i}$; the ARCH term $u_{i, t-1}^{2}$ (i.e. the squared residuals from the previous period), which represents the impact of new information about volatility from the previous period; and the GARCH term $\sigma_{i, t-1}^{2}$, representing the impact of forecast variance from the previous period. The attractiveness of the $\operatorname{GARCH}(1,1)$ model is that it can capture the persistence of the conditional variances in a more parsimonious manner than higher-order ARCH processes. The use of conditional variance estimated from GARCH type models, as a statistical measure of uncertainty is widely used in studies employing the standard monetary model with asymmetric central bank preferences (see e.g., RugeMurcia (2003, 2004); Sweidan (2009), Doyle and Falk (2010) and Cassou et al. (2012)).

In this paper, $\sigma_{y t}^{2}$ series is generated from an output gap equation ${ }^{8}$, estimated as an ARMA $(1,2)$ which is selected by the Akaike and Schwarz information criteria, out of a number of selected $\operatorname{ARMA}(\mathrm{p}, \mathrm{q})$ specifications. We use the Phillips curve equation $\pi_{t}=\pi_{t}^{e}+(1 / \kappa) y_{t}-(1 / \kappa) u_{t}$ to estimate the series for $\sigma_{\pi t}^{2}$. However, as suggested by Rudd and Whelan (2005), the pure forward looking Phillips curve is empirically

\footnotetext{
${ }^{7}$ Nominal GNP (as suggested in part of the literature - see e.g., Lucas (1973) Abbott and Martínez (2008) was also used as an alternative measure of aggregate demand. The results are similar to that of money supply, and are available upon request.

${ }^{8}$ In specifying a reduced form process for the output gap, we follow the approach used in the literature whereby it is shown that, in a framework such as ours, output can be represented as an ARMA process i.e. as a function of its past realizations and a linear combination of current and past structural shocks. We refer the reader to Ruge-Murcia (2003pp1383) and Cassou et al. (2012 pp655) for the details.
} 
unimportant in explaining inflation behaviour. Thus, as in Galí and Gertler (1999) a fraction of firms are forward looking; so that by imposing rational expectations, as in Linde (2005) the equation that is used to generate the $\sigma_{\pi t}^{2}$ series is amended to be

$$
\pi_{t}=\hat{\theta}_{\pi, 1} \pi_{t-1}+\hat{\theta}_{\pi, 2} \pi_{t-2}+\hat{\theta}_{y} y_{t}+\varepsilon_{t}^{\pi}
$$

Finally, the series for the measure of unanticipated monetary policy shock $\sigma_{m t}^{2}$ is generated from the residuals of equation (5). Table 1 presents the OLS and GARCH $(1,1)$ estimates of the inflation, output gap and money supply equations. The LM test statistics for neglected ARCH are given for the first two lags in each regression. For the OLS regressions, the null hypothesis of no conditional heteroskedasticity is rejected whereas it is not rejected for the GARCH $(1,1)$ specifications. It would appear then that the parsimonious GARCH $(1,1)$ model adequately captures the conditional heteroskedasticity in the inflation, money and output gap series.

The evolution of the variables i.e. inflation rate, money supply, output gap and their estimated conditional variances are depicted in Figure 1. It is seen that inflation begun to rise after 2001 peaking towards the end of 2002 before falling sharply, reaching its minimum ever in 2003. It subsequently rose steadily thereafter until mid-2008 before declining gradually and remaining within the target range at the end of the sample. The coincidental business cycle indicator has fairly remained stable from the start of the sample up until the period of the global financial crises in 2007-08, after which it fell significantly reaching an all-time low in mid-2009. There has been steady recovery thereafter until the end of the sample. It is no surprise that the period of high volatility in inflation and the measure of output gap coincided with the period of the subprime crisis in 2007-08 and the subsequent recession that followed in 2009. Over the sample period the growth in broad money supply seems somewhat related to the measure of economic activity.

Our analytical results as analyzed in section II hypothesize that uncertainty in the Phillips curve tradeoff helps to explain inflation dynamics. Model estimation is carried out along the lines of the inflationunemployment model of Ruge-Murcia (2003, 2004) using Maximum Likelihood procedure ${ }^{9}$. The idea here is to estimate simultaneously a system of two reduced form equations, one for inflation and the other for output gap. Notice that we have derived in section II three variants of the reduced form equations for inflation i.e. equation (10) for quadratic central bank preferences, equation (16) for asymmetric preferences over inflation stabilization only, and equation (22) for asymmetric preferences over both inflation and output stabilization. Following

\footnotetext{
${ }^{9}$ Ruge-Murcia $(2003,2004)$ notes that a two-step procedure in which OLS is applied to the reduced form equation of inflation after the conditional variances are estimated as the first step, yield similar, but the estimates are less efficient than the Maximum Likelihood estimates.
} 
Ruge-Murcia (2004) ${ }^{10}$ each of these three reduced form equations for inflation is estimated simultaneously with an autoregressive form of the first difference of the output gap equation. A lag length of 2 is chosen, as it yields better fit in terms of AIC than other AR representations. In other related work Sweidan (2009), for instance estimates a distributed-lag model of reduced form equation for inflation using OLS.

\section{B. Results}

The Full Information Maximum Likelihood (FIML) estimates of inflation process ${ }^{11}$ for our different specifications are reported in Table 2, with columns (i) and (ii) showing the results of the model in which central bank preferences are quadratic over inflation and output deviation from target. Columns (iii) and (iv) depict the results of the model with asymmetric preference to inflation deviation from target but symmetric to output fluctuations from potential. Columns (v) and (vi) show the results of the model with asymmetric preferences to both inflation and output deviations from target. We however focus the discussion of the results on the three models with uncertainty i.e. models (ii), (iv) and (vi), and only consider the models under certainty equivalence i.e. model (i), (iii) and (v) as the benchmark models for the respective cases. In all models the parameter estimate of $\hat{\rho}_{0}$ is approximately $6 \%$, which corresponds to the average rate of inflation over the sample period considered. On average, the signs of the coefficients across all models are consistent with the theoretical predictions as described in section II. The difference across the models lies in the magnitude of these coefficients. In particular, the models with asymmetric preferences yields relatively smaller parameter estimates relative to the model with quadratic preferences.

Across all models (with uncertainty), and consistent with the inflation-output trade-off, the estimate of $\hat{\rho}_{1}$ is negative and statistically significant implying that the central banker responds to a positive output deviation from potential by adopting a contractionary monetary policy. As earlier alluded in the theoretical analysis in section II, when the policymaker is uncertain about the inflation-output trade-off, inflation will depend on the interaction (product) of output gap and volatility of monetary policy. $\hat{\rho}_{2}$ quantifies this effect empirically, and is found to be positive and insignificant for the model with asymmetric preference to both inflation and output gap. Following up specifically on the analysis in section II, sub-section C, the estimate of

\footnotetext{
${ }^{10}$ Ruge-Murcia's (2004) model comprise a system of a reduced form for inflation and either an $\operatorname{ARIMA}(2,0,2)$ or an $\operatorname{ARIMA}(2,1,2)$ representation for unemployment depending on the assumption placed on the stationarity of unemployment. However, the author reckons that since any stationary ARMA process can be approximated arbitrarily well by a finite autoregression, and the estimation of ARMA process is often complicated by common factors, then the first difference of unemployment can be estimated in autoregressive form.

${ }^{11}$ In the interest of space and so as to stick with to theme of this paper, we do not report the estimates of the output gap process, but they are available from the authors upon request.
} 
$\hat{\rho}_{2}$ indicates that, for a given level of output gap, an increase in the volatility of monetary policy leads to a higher inflation rate. The implication of this is that the shock variance causes a steeper output-inflation trade-off of the economy's aggregate supply curve: that is, higher fluctuations in aggregate demand causes fluctuations in the aggregate price level, and agents (producers) will have known that the movement in prices in the economy is due to an aggregate shock, causing them not to adjust output. Indeed in our Lucas-type model, higher volatility in monetary policy may cause temporary disequilibrium in the economy (including the price level), and this may persist until equilibrium is restored. In other words, misperceptions of inflation that arise from excessive changes in monetary policy may lead to periods of adjustments in the economy (including prices), during which time inflation rates are higher.

Relative to the model with quadratic preferences (column (ii)), the model with asymmetric preference to inflation (in column (iv)) has an additional parameter estimate, $\hat{\rho}_{3}$. The coefficient is negative and statistically significant at the 5 percent level suggesting that uncertainty due to central bank asymmetric aversion to inflation stabilization is important in explaining inflation dynamics. In particular, an increase in the volatility of inflation will cause the Reserve bank to lower the average inflation rate. The negative sign of $\hat{\rho}_{3}$ implies that the sign of the preference parameter that measures the degree of asymmetry over inflation stabilization, $\alpha$ is positive, (since $\rho_{3}=-(\alpha / 2)$ ), indicating that the Reserve bank dislikes high inflation more than she dislikes low inflation rate i.e. it has a deflationary bias. This result supports Nobay and Peel (2003) theoretical model for the European Central Bank (ECB), as well as the estimated nonlinear Taylor rules of Naraidoo and Paya (2012) for South Africa and Milas and Naraidoo (2012) for the ECB. Intuitively, this result (deflationary bias) implies that since the monetary authority is uncertain about the state of the economy and is more worried about making policy mistakes that would push inflation above the target, it will intensify its attempts to stabilize inflation (relative to output), so that the overall rate inflation is lower.

The estimates of the inflation process under asymmetric preferences to both inflation and output are reported in column (vi). Like the model with asymmetric aversion to inflation only in column (iv), $\hat{\rho}_{3}$ is negative and statistically significant, and is consistent with the view that the central bank is dislikes inflationary more than deflationary pressures. The estimated coefficient of the conditional variance of output, $\hat{\rho}_{4}$ is negative and statistically insignificant, meaning that SARB's asymmetric aversion toward output stabilization is not important in interpreting inflation movements. Since $\rho_{4}=\left(-\lambda \gamma v_{0}\right) / 2$ (from section II, sub-section E), the 
estimated value of $\hat{\rho}_{4}$ of -0.51 the magnitude of the preference parameter $\gamma$ is not identified, (because $\lambda$ and $v_{0}$ are unknown). However, the estimate suggests that $\gamma$ is positive. This could be interpreted to mean that the monetary authority is willing to tolerate an output level that is below the potential and penalize positive deviations of output from the potential level. Therefore, we may conclude that since $\hat{\rho}_{3}$ and $\hat{\rho}_{4}$ are both negative (implying $\alpha>0$ and $\gamma>0$ ) the Reserve bank seems to dislike high inflation (relative to target) and dislike high output (relative to potential level) i.e. has an deflationary bias.

In comparing the results across the different models fitted in Table 2, one observes that the models with uncertainty i.e. (ii), (iv) and (vi) dominate in terms of overall goodness of fit, therefore rationalizing the importance of taking into account uncertainty in the output-inflation trade-off in describing inflation behaviour. For the models with asymmetric preferences, it is worth noting that most of the estimates from the model with asymmetric preferences to both inflation and output (in column (vi)) are insignificant, suggesting that this model fits the data poorly (relative to the model with asymmetric aversion to inflation only, in column (iv)). Furthermore, model (iv) displays better AIC and log-likelihood values as well as smaller standard error than model (vi). As such, it is imperative to interpret the results for asymmetric preferences in column (vi) with some degree of caution. Finally, relative to the model with asymmetric aversion to inflation i.e. (iv), the model with quadratic preference i.e. (ii) seems to perform better in terms of the AIC and standard error (except for the loglikelihood). This implies that by taking into account the uncertainty in output-inflation trade-off, central bank quadratic preferences may as well be justified.

In spite of the above, we believe that the results from this study are generally consistent with existing literature, and to a certain extent helpful to tell a story about how uncertainty in monetary policy would be useful in interpreting inflation movements in South Africa. The Reserve bank's preferences are found to be more inclined toward lower inflation rates (deflationary bias). Not only is this consistent with SARB's primary mandate of maintaining price stability, but would also be critical in lowering volatility in the economy.

\section{Conclusion}

The paper has examined the likely impact of uncertainty about the output-inflation trade-off for the behaviour of inflation when central bank preferences are asymmetric over inflation and output. The uncertainty is modelled using the Lucas (1973) signal extraction model, in which slope of the Phillips curve varies with the uncertainty about monetary policy. We estimated various versions of the model with Maximum Likelihood using South 
African data on inflation, output gap and money supply. The study is particularly relevant for South Africa, which has since adopted inflation targeting as the anchor for monetary policy from the year 2000 .

We have shown that in general, the models with uncertainty dominate those with certainty equivalence in terms of overall goodness of fit. Additionally, considering the models with asymmetric preferences, the data seems to favour the model with central bank asymmetric aversion to inflation only, perhaps justifying the primary role of maintaining price stability on the part of the SARB. Overall the empirical results underscore the significant role that central bank asymmetric aversion to inflation plays in explaining inflation movement in South Africa. These preferences give room for uncertainty over inflation to influence inflation patterns. We also find evidence showing that the Reserve bank seems to penalize more for inflationary rather than deflationary pressures, consistent with the deflation bias hypothesis. This supports results from other studies (see e.g. Nobay and Peel (2003), Naraidoo and Paya (2012) and Milas and Naraidoo (2012)). Furthermore, it is found that the models with asymmetric preferences yield relatively smaller coefficients relative to the one under quadratic preferences. This would suggest that since the monetary authority places more weight on positive deviation of inflation from target, inflation movements over the sample period considered are restrained, on average.

The main contribution of this paper nonetheless, is on the role that uncertainty about output-inflation trade-off plays in explaining inflation behaviour. Firstly, the uncertainty causes an additional determinant i.e. an interaction of output and volatility of monetary policy to explain inflation movements: specifically, we find that higher volatility in monetary policy causes inflation to increase significantly. Secondly, as suggested in an optimal rule, this uncertainty causes output to decrease by less whenever inflation increases above the target, and to increase by less whenever inflation is below the target i.e. it induces a more lenient approach to reducing inflation on the part of the monetary authority. Overall, the study shows that SARB's deflationary bias seems, not only to be consistent with the bank's primary mandate of maintaining price stability, but also as important in keeping the economy away from any unlikely consequences of volatile inflation. 
Figures and Tables

Figure 1. Evolution of the variables
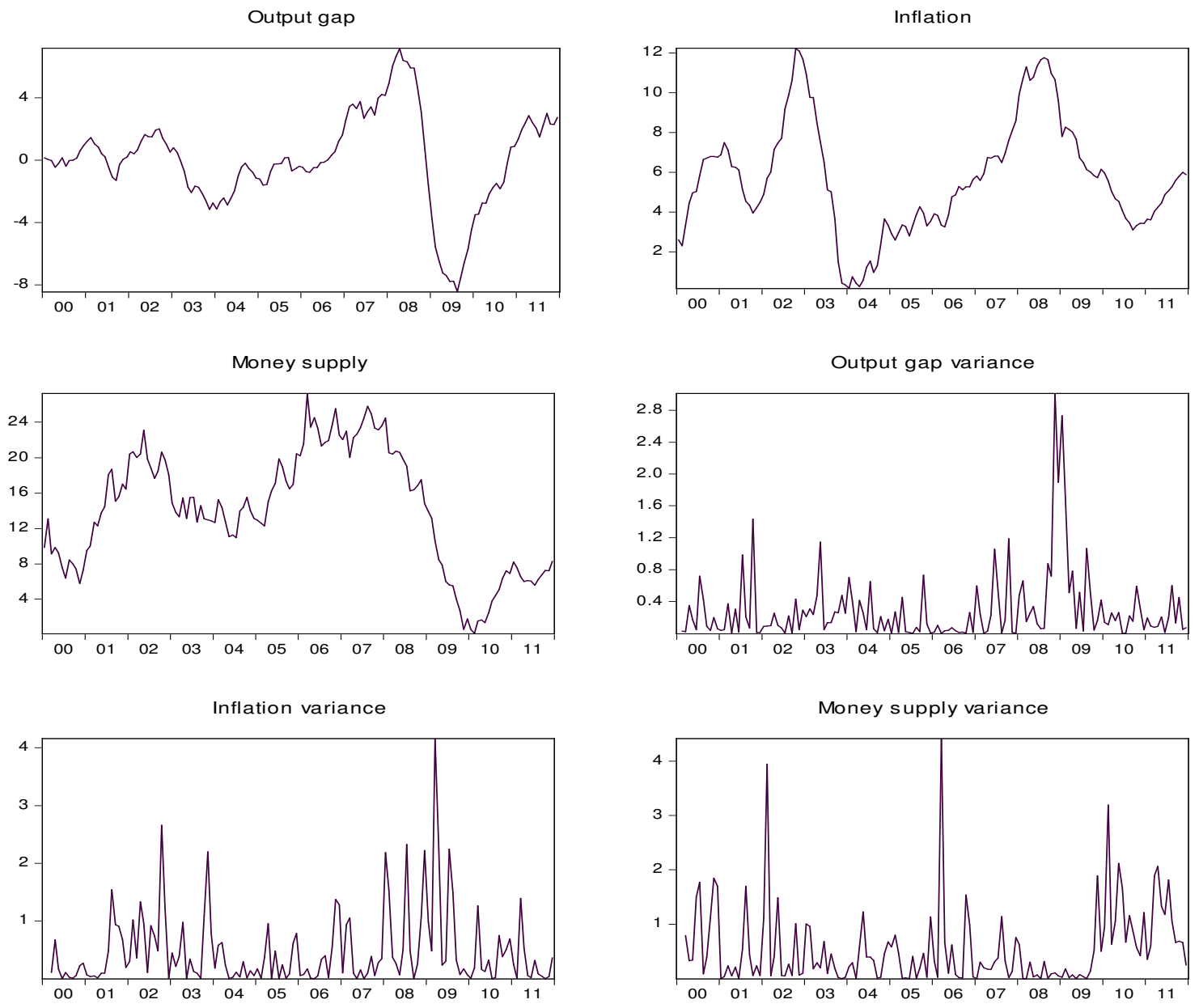
Table 1: OLS and GARCH estimates

\begin{tabular}{|c|c|c|c|c|c|c|}
\hline \multirow{2}{*}{$\begin{array}{l}\text { Coefficient } \\
\text { Mean equation }\end{array}$} & \multicolumn{2}{|c|}{ (i) Inflation } & \multicolumn{2}{|c|}{ (ii) Output gap } & \multicolumn{2}{|c|}{ (iii) Money supply } \\
\hline & OLS & $\operatorname{GARCH}(1,1)$ & OLS & $\begin{array}{c}\text { GARCH } \\
(1,1)\end{array}$ & OLS & $\begin{array}{c}\text { GARCH } \\
(1,1)\end{array}$ \\
\hline$\hat{\theta}_{\pi, 1}$ & $\begin{array}{l}1.394^{* * *} \\
(0.077)\end{array}$ & $\begin{array}{l}1.346^{* * *} \\
(0.101)\end{array}$ & & & & \\
\hline$\hat{\theta}_{\pi, 2}$ & $\begin{array}{c}0.450^{* * *} \\
(0.074)\end{array}$ & $\begin{array}{c}0.393^{* * *} \\
(0.092)\end{array}$ & & & & \\
\hline$\hat{\theta}_{y}$ & $\begin{array}{c}0.046^{*} \\
(0.017)\end{array}$ & $\begin{array}{l}0.036^{*} \\
(0.022)\end{array}$ & & & & \\
\hline $\mathrm{AR}(1)$ & & & $\begin{array}{c}0.955^{\star \star \star} \\
(0.027)\end{array}$ & $\begin{array}{c}0.939^{* * *} \\
(1.053)\end{array}$ & & \\
\hline $\mathrm{MA}(1)$ & & & $\begin{array}{c}0.464^{* * *} \\
(0.085)\end{array}$ & $\begin{array}{c}0.416^{* * *} \\
(0.099)\end{array}$ & & \\
\hline $\mathrm{MA}(2)$ & & & $\begin{array}{c}0.285^{\star * *} \\
(0.085)\end{array}$ & $\begin{array}{l}0.194^{*} \\
(0.104)\end{array}$ & & \\
\hline$\hat{\tau}_{1}$ & & & & & $\begin{array}{l}0.267^{* * *} \\
(0.069)\end{array}$ & $\begin{array}{l}0.356^{\star * *} \\
(0.065)\end{array}$ \\
\hline$\hat{\tau}_{2}$ & & & & & $\begin{array}{c}0.350^{* * *} \\
(0.069)\end{array}$ & $\begin{array}{c}0.440^{* * *} \\
(0.085)\end{array}$ \\
\hline$\hat{\tau}_{3}$ & & & & & $\begin{array}{l}0.002^{* *} \\
(0.001)\end{array}$ & $\begin{array}{c}0.001 \\
(0.0001)\end{array}$ \\
\hline \multicolumn{7}{|l|}{$\begin{array}{l}\text { Variance } \\
\text { equation }\end{array}$} \\
\hline Constant & & $\begin{array}{c}0.002 \\
(0.006)\end{array}$ & & $\begin{array}{c}0.030 \\
(0.029)\end{array}$ & & $\begin{array}{c}0.0004 \\
(0.0002)\end{array}$ \\
\hline $\operatorname{Resid}(-1)^{\wedge} 2$ & & $\begin{array}{l}0.209^{* *} \\
(0.092)\end{array}$ & & $\begin{array}{l}0.157^{\star} \\
(0.101)\end{array}$ & & $\begin{array}{l}0.292^{\star \star} \\
(0.119)\end{array}$ \\
\hline $\mathrm{GARCH}(-1)$ & & $\begin{array}{c}0.798^{* * *} \\
(0.089)\end{array}$ & & $\begin{array}{c}0.743^{* * *} \\
(0.190)\end{array}$ & & $\begin{array}{c}0.639^{* * *} \\
(0.152)\end{array}$ \\
\hline$R^{2}$ & 0.968 & 0.968 & 0.967 & 0.967 & 0.903 & 0.903 \\
\hline Std error & 0.511 & 0.512 & 0.543 & 0.549 & 0.631 & 0.645 \\
\hline \multicolumn{7}{|l|}{$\begin{array}{l}\text { LM tests for } \\
\text { neglected } \\
\text { ARCH }\end{array}$} \\
\hline $\begin{array}{l}1 \text { lag } \\
2 \text { lags }\end{array}$ & $\begin{array}{c}3.949 \\
(0.046) \\
9.520 \\
(0.023) \\
\end{array}$ & $\begin{array}{l}0.091(0.764) \\
1.291(0.524)\end{array}$ & $\begin{array}{c}17.70 \\
(0.000) \\
19.43 \\
(0.000) \\
\end{array}$ & $\begin{array}{c}0.095 \\
(0.954) \\
0.649 \\
(0.956) \\
\end{array}$ & $\begin{array}{c}17.01 \\
(0.000) \\
17.00 \\
(0.001) \\
\end{array}$ & $\begin{array}{c}0.128 \\
(0.721) \\
0.542 \\
(0.763) \\
\end{array}$ \\
\hline
\end{tabular}

Note: As described in the text, equation (24) is the estimated inflation process; an ARMA $(1,2)$ is fitted for the output gap equation, as chosen by the Akaike and Schwarz information criteria; and for the money supply process equation (5) is estimated. In testing the squared residuals of the estimated GARCH models, we perform the Lagrange multiplier (LM) tests for neglected serial correlation, and report only test statistics up to the second order, with the corresponding probabilities reported in brackets. The ARCH test is the Engle (1982) ARCH LM test which tests the null hypothesis of no ARCH up to order $q$ in residuals. 
Table 2. FIML estimates of inflation process

\begin{tabular}{|c|c|c|c|c|c|c|}
\hline \multirow{3}{*}{ Coefficient } & \multicolumn{6}{|c|}{ Model } \\
\hline & \multicolumn{2}{|c|}{$\begin{array}{l}\text { Case 1: Quadratic } \\
\text { preferences }\end{array}$} & \multicolumn{2}{|c|}{$\begin{array}{l}\text { Case 2: Asymmetric } \\
\text { preferences to inflation }\end{array}$} & \multicolumn{2}{|c|}{$\begin{array}{l}\text { Case 3: Asymmetric } \\
\text { preferences to inflation and }\end{array}$} \\
\hline & (i) Certainty & (ii) Uncertainty & (iii) Certainty & (iv) Uncertainty & (v) Certainty & $\begin{array}{l}\text { (vi) } \\
\text { Uncertainty }\end{array}$ \\
\hline$\hat{\rho}_{0}$ & $\begin{array}{l}6.116^{* * *} \\
(0.354)\end{array}$ & $\begin{array}{l}5.992^{* * *} \\
(0.344)\end{array}$ & $\begin{array}{l}6.429^{* * *} \\
(0.437)\end{array}$ & $\begin{array}{l}6.151^{* * *} \\
(0.387)\end{array}$ & $\begin{array}{l}6.267^{* * *} \\
(0.487)\end{array}$ & $\begin{array}{l}6.308^{* * *} \\
(0.422)\end{array}$ \\
\hline$\hat{\Omega}$ & -0.185 & $-0.184^{\star *}$ & $-0.182^{*}$ & $-0.179^{\star *}$ & $-0.166^{\star}$ & $-0.160^{* *}$ \\
\hline$\mu_{1}$ & $(0.067)$ & $(0.076)$ & $(0.065)$ & $(0.076)$ & $(0.065)$ & $(0.722)$ \\
\hline$\hat{\rho}_{2}$ & & $0.163^{\star * *}$ & & $0.146^{\star * *}$ & & 0.083 \\
\hline & & & $-0206^{* *}$ & $\begin{array}{l}(0.044) \\
-0136 * *\end{array}$ & $-0203^{* *}$ & $\begin{array}{c}\text { (0.056) } \\
-0236^{\star *}\end{array}$ \\
\hline$\rho_{3}$ & & & $(0.100)$ & $(0.079)$ & $(0.102)$ & $(0.096)$ \\
\hline$\hat{\rho}_{4}$ & & & & & 0.146 & -0.510 \\
\hline$\rho_{4}$ & & & & & $(0.169)$ & $(0.321)$ \\
\hline$\hat{\rho}_{5}$ & & & & & & 1.020 \\
\hline & & & & & & $(0.661)$ \\
\hline $\begin{array}{l}\text { Standard } \\
\text { Error }\end{array}$ & 2.75 & 2.67 & 2.79 & 2.71 & 2.78 & 2.77 \\
\hline $\mathrm{AIC}$ & -2.59 & -2.60 & -2.56 & -2.58 & -2.55 & -2.56 \\
\hline $\begin{array}{l}\text { Log- } \\
\text { likelihood }\end{array}$ & 204.04 & 188.54 & 194.96 & 187.86 & 195.27 & 192.27 \\
\hline $\begin{array}{l}\text { J-Bera } \\
\text { (p-value) }\end{array}$ & $\begin{array}{l}5.46 \\
(0.24)\end{array}$ & $\begin{array}{c}3.94 \\
(0.13)\end{array}$ & $\begin{array}{c}9.57 \\
(0.08)\end{array}$ & $\begin{array}{c}4.40 \\
(0.16)\end{array}$ & $\begin{array}{l}8.31 \\
(0.08)\end{array}$ & $\begin{array}{l}3.01 \\
(0.22)\end{array}$ \\
\hline
\end{tabular}

Note: Equation (10) in the text, is the fitted model under quadratic preference i.e. in column (ii); under asymmetric preference to inflation as shown in column (iv), the estimated equation is (16) in the text; whereas for the model under asymmetric preferences to both inflation and output as depicted by results in column (vi), the fitted equation is (22) in the text. Columns (i), (iii) and (v) respectively depicts the results of these three models, but under certainty equivalence. $\hat{\rho}_{0}$ is the intercept term. The figures in parenthesis are standard errors. ${ }^{* *}$ and ${ }^{* *}$ respectively, denote rejection of the null hypothesis that the true coefficient is zero at the $1 \%$ and $5 \%$ level of significance. The J-Bera statistic tests the null hypothesis that the residuals from the system of equations are multivariate normal. It is seen that the null is not rejected for the models under uncertainty, i.e. (ii), (iv) and (vi). 


\section{Appendix A: The Phillips curve under signal extraction}

In the Lucas (1973) model, the economy consists of $N$ 'islands' indexed by $i$. We start with 'island's' incomplete information supply curve

$$
Y_{i t}=Y^{*}+\theta\left(P_{i t}-E\left\{P_{t} / P_{i t}\right)\right.
$$

Here, producer's own price ( $P_{i t}$ ) differs only randomly from the aggregate price $\left(P_{t}\right)$ i.e.

$$
P_{i t}=P_{t}+z_{i t}
$$

$z_{i t}$ represents any 'local' productivity shock with zero mean and variance $\sigma_{z}^{2}$. Similarly,

$$
P_{t}=P^{*}+\varepsilon_{t}
$$

$\varepsilon_{t}$ is a random aggregate shock to prices. Combing (A2) and (A3) gives $P_{i t}=P^{*}+\varepsilon_{t}+z_{i t}$ which implies that a producer does not know whether the change in its own price is due to changes in overall prices or from relative prices. The problem faced by each producer in the 'island' is to forecast $P_{t}-E\left\{P_{t} / P_{i t}\right\}$ using $P_{i t}-E\left\{P_{t} / P_{i t}\right\}$. In order to solve for $E\left\{P_{t} / P_{i t}\right\}$ we restrict the analysis to linear expectations and consider the Best Linear Unbiased Estimator (BLUE) of $P_{t}$ on $P_{i t}$ i.e.

$$
E\left\{P_{t} / P_{i t}\right\}=\phi_{0}+\phi_{1} P_{i t}+v_{t}
$$

so that, we minimize the mean squared error $\sum v_{t}^{2}$. The residuals from the regression will satisfy the conditions: $E\left\{v_{t}\right\}=E\left\{P_{t}-\phi_{0}-\phi_{1} P_{i t}\right\}=0$; and $E\left\{v_{t} P_{i t}\right\}=E\left\{\left(P_{t}-\phi_{0}-\phi_{1} P_{i t}\right) P_{i t}\right\}=0$. We need to solve for $\phi_{0}$ and $\phi_{1}$. First, we note that, noting the following:,

$$
\begin{aligned}
& E\left\{P_{t}\right\}=\phi_{0}+\phi_{1} E\left\{P_{i t}\right\} \\
& E\left\{P_{i t}\right\}=E\left\{P_{t}+z_{i t}\right\}=E\left\{P_{t}\right\}=P^{*} \quad \text { (from (A4)) }
\end{aligned}
$$

By combining (A5) and (A6), we have

$$
P^{*}=\frac{\phi_{0}}{1-\phi_{1}}
$$

Further, equation (A.5) also implies that $E\left\{P_{t} P_{i t}\right\}=\phi_{0} E\left\{P_{i t}\right\}+\phi_{1} E\left\{\left(P_{i t}\right)^{2}\right\}$ from which we can substitute (A2) and (A3) into it, to give 


$$
E\left\{P_{t} P_{i t}\right\}=\left(P^{*}\right)^{2}+\sigma_{\varepsilon t}^{2}
$$

In the same way,

$$
E\left\{\left(P_{i t}\right)^{2}\right\}=\left(P^{*}\right)^{2}+\sigma_{\varepsilon t}^{2}+\sigma_{z t}^{2}
$$

As motivated in the text, note that in equations (A8) and (A9), and henceforth we have introduced a time subscript on the variances of the shocks in order to account for the fact that, over time the fluctuations in aggregate demand (important in determining the slope of the aggregate supply curve in this paper) varies. Next, using (A8) and (A9) in $E\left\{P_{t} P_{i t}\right\}=\phi_{0} E\left\{P_{i t}\right\}+\phi_{1} E\left\{\left(P_{i t}\right)^{2}\right\}$, bearing in mind that $\phi_{0}=P^{*}\left(1-\phi_{1}\right)$ from (A7), the solutions for $\phi_{0}$ and $\phi_{1}$ are

$$
\phi_{0}=\frac{P^{*} \sigma_{z t}^{2}}{\sigma_{z t}^{2}+\sigma_{\varepsilon t}^{2}} \quad \text { and } \quad \phi_{1}=\frac{\sigma_{\varepsilon t}^{2}}{\sigma_{\varepsilon t}^{2}+\sigma_{z t}^{2}}
$$

These two solutions can be substituted into (A4), so that

$$
E\left\{P_{t} / P_{i t}\right\}=P^{*}+\frac{\sigma_{\varepsilon t}^{2}}{\sigma_{\varepsilon t}^{2}+\sigma_{z t}^{2}}\left(P_{i t}-P^{*}\right)
$$

Replacing (A10) into the supply curve in (A1) gives

$$
Y_{i t}=Y^{*}+\frac{\theta \sigma_{z t}^{2}}{\sigma_{z t}^{2}+\sigma_{z t}^{2}}\left(P_{i t}-P^{*}\right)
$$

which can then be aggregated across all producers in the economy to give the Lucas supply curve under imperfect information, as in equation (2) in the text.

Now, we need to motivate the linear specification of $\kappa_{t}$ in equation (4) which derives from $\kappa_{t}=\frac{\theta \sigma_{z t}^{2}}{\sigma_{z t}^{2}+\sigma_{\varepsilon t}^{2}}$. We may use the approximation of the ratio of the variance of each of the observables to the total variance of the observables by taking the log first differences i.e.

$$
d \ln \kappa_{t}=d \ln \sigma_{z t}^{2}-d \ln \left(\sigma_{z t}^{2}+\sigma_{\varepsilon t}^{2}\right)
$$

Using the approximation

$$
d \ln (x+y) \cong \frac{x_{0}}{x_{0}+y_{0}} d \ln x+\frac{y_{0}}{x_{0}+y_{0}} d \ln y
$$

for the second term in (A13). We now have 


$$
d \ln \kappa_{t}=d \ln \sigma_{z t}^{2}-d \ln \left(\frac{\sigma_{z 0}^{2}}{\sigma_{z 0}^{2}+\sigma_{\varepsilon 0}^{2}} d \ln \sigma_{z t}^{2}+\frac{\sigma_{\varepsilon 0}^{2}}{\sigma_{z 0}^{2}+\sigma_{\varepsilon 0}^{2}} d \ln \sigma_{\varepsilon t}^{2}\right)
$$

Integrating throughout yields the following equation

$$
\ln \kappa_{t}=\left(1-\frac{\sigma_{z 0}^{2}}{\sigma_{z 0}^{2}+\sigma_{\varepsilon 0}^{2}}\right) \ln \sigma_{z t}^{2}-\frac{\sigma_{\varepsilon 0}^{2}}{\sigma_{z 0}^{2}+\sigma_{\varepsilon 0}^{2}} \ln \sigma_{\varepsilon t}^{2}+\text { cons } \tan t
$$

where constant represents the constant of integration. Equation can be further simplified as

$$
\ln \kappa_{t}=v_{0}+v_{1} \ln \sigma_{z t}^{2}+v_{2} \ln \sigma_{z t}^{2}
$$

where $v_{0}=$ cons $\tan t, v_{1}=-\frac{\sigma_{\varepsilon 0}^{2}}{\sigma_{z 0}^{2}+\sigma_{\varepsilon 0}^{2}}$ and $v_{2}=1-\frac{\sigma_{z 0}^{2}}{\sigma_{z 0}^{2}+\sigma_{\varepsilon 0}^{2}}$.

Taking the exponential function of (A16), i.e. $\exp \left(\ln \kappa_{t}\right)=\exp \left(v_{0}+v_{1} \ln \sigma_{z t}^{2}+v_{2} \ln \sigma_{\varepsilon t}^{2}\right)$ gives

$$
\kappa_{t}=v_{0}\left(\sigma_{\varepsilon t}^{2}\right)^{v_{1}}\left(\sigma_{z t}^{2}\right)^{v_{2}}
$$

which is an approximation of $\kappa_{t}$ in the case of multiplicative variance terms. We however leave this form for further research, and consider in this paper an alternative additive case ${ }^{12}$, given as

$$
\kappa_{t}=v_{0}+\nu_{1} \sigma_{\varepsilon t}^{2}+v_{2} \sigma_{z t}^{2}
$$

\section{Appendix B: Effects of money supply shocks}

In order to show that changes in money supply only affect prices, we can re-write our aggregate supply curve in (2) in lower case variables to denote natural logs (while dropping the i.i.d. shock in the equation, as a way of simplifying the derivations), as

$$
y_{t}=y_{t}^{N}+\kappa_{t}\left(p_{t}-p_{t}^{e}\right)
$$

Note that we can let $y_{t}^{N} \equiv y^{N}$. Knowing that aggregate demand side of the model arises from an equation of exchange (quantity theory of money) i.e. $M V=P Y$, which in natural logs implies

$$
y_{t}=m_{t}+v_{t}-p_{t}
$$

\footnotetext{
${ }^{12}$ The additive case we use in this paper (equation A18) is analogous to the log-linear approximation in equation (A16), although we do not use the natural logarithm of the variances in the estimation. The idea here is to provide a basis to motivate a linear relationship between $\kappa_{t}$ and the variances of the shocks $\sigma_{\varepsilon t}^{2}$ and $\sigma_{z t}^{2}$. We leave the multiplicative case (equation A17) for future research.
} 
This equation implies an inverse relationship between price and output which is the essential feature of aggregate demand. Solving for prices in (A20) and taking expectations, we have

$$
p_{t}^{e}=E_{t} m_{t}+E_{t} v_{t}-E_{t} y_{t}
$$

Then from (A20) and (A21) it implies

$$
p-p_{t}^{e}=m_{t}-E_{t} m_{t}+\left(v_{t}-E_{t} v_{t}\right)-\left(y_{t}-E_{t} y_{t}\right)
$$

With constant velocity of money and $y_{t}-E_{t} y_{t}=\kappa_{t}\left(p_{t}-p_{t}^{e}\right)$ from (A20), it means that

$$
p-p_{t}^{e}=m_{t}-E_{t} m_{t}-\kappa_{t}\left(p_{t}-p_{t}^{e}\right)
$$

This reduces to

$$
p-p_{t}^{e}=\frac{1}{1+\kappa_{t}}\left(m_{t}-E_{t} m_{t}\right)
$$

This equation means that surprises in prices purely arise from unanticipated surprises in money (or unanticipated shocks to aggregate demand in general). 


\section{References}

Abbott, Brant, and Cristina Martínez (2008). An updated assessment of the Lucas supply curve and the inflation-output trade-off. Economic Letters 101: 199-201.

Apergis, Nicholas, and Stephen Miller (2004). Macroeconomic rationality and Lucas's misperceptions model: further evidence from forty-one countries. Journal of Economics and Business 56: 227-241.

Ball, Lawrence, Gregory N. Mankiw, and David Romer (1988). New Keynesian Economics and the outputinflation trade-off. Brookings Papers on Economic Activity.

Ball, Lawrence, and Sandeep Mazumder (2011). Inflation dynamics and the Great recession. Brookings Papers on Economic Activity, Spring 2011.

Barro, Robert J. (1977). Unanticipated money growth and unemployment in the United States. American Economic Review 67: 101-115.

Barro, Robert J., and David B. Gordon (1983). Rules, discretion and reputation in a model of monetary policy. Journal of Monetary Economics 12: 101-122.

Bollerslev, Tim (1986). Generalized autoregressive conditional heteroskedasticity. Journal of Econometrics 31: 307-327.

Brainard, William (1967). Uncertainty and the effectiveness of policy. American Economic Review 57: 411-25.

Cassou, Stephen. P., C. Patrick Scott, and Jesús Vázquez (2012). Optimal monetary policy with asymmetric preferences for output. Economic Letters 117: 654-656.

Cukierman, Alex (2000). The inflation bias result revisited. Tel-Aviv University, Mimeo.

De Veirman, Emmanuel. (2007). Which nonlinearity in the Phillips curve? the absence of accelerating deflation in Japan. Economics Working Paper 536. The Johns Hopkins University, Department of Economics.

Doyle, Matthew, and Barry Falk (2010). Do asymmetric central bank preferences help explain observed inflation outcomes. Journal of Macroeconomics 32: 527-540.

Engle, Robert F. (1982). Autoregressive conditional heteroskedasticity with estimates of the variance of United Kingdom inflation. Econometrica 50: 987-1007.

Friedman, Milton. (1968). The role of monetary policy. American Economic Review 58: 1-17.

Galı’, Jordi, and Mark Gertler. (1999). Inflation dynamics: a structural econometric analysis. Journal of Monetary Economics 44: 195-222.

Giannoni, Marc P. (2002). Does model uncertainty justify caution? Robust optimal monetary policy in a forward-looking model. Macroeconomic Dynamics 6: 111-144. 
Glick, Reuven, and Michael Hutchison (1990). New results in support of the fiscal policy ineffectiveness proposition. Journal of Money, Credit, and Banking 22: 288-304.

Hodrick, J. Hodrick, and Edward C. Prescott, (1997). Postwar U.S. Bbusiness cycles: an empirical investigation. Journal of Money, Credit and Banking 29: 1-16.

Kasaï, Ndahiriwe, and Ruthira Naraidoo (2013). The opportunistic approach to monetary policy and financial market conditions. Applied Economics 45: 2537-2545.

Kimura, Takeshi, and Takushi Kurozumi (2007). Optimal monetary policy in a micro-founded model with parameter uncertainty. Journal of Economic Dynamics and Control 31: 399-431.

Kormendi, Roger C., and Phillip Meguire, (1991). Cross-country tests of the Lucas proposition revisited: a comment. Journal of Business \& Economic Statistics 9: 151-159.

Linde, Jesper (2005). Estimating New-Keynesian Phillips curves: a full information maximum likelihood approach. Journal of Monetary Economics 52: 1135-1149.

Lucas Jr, Robert E. (1973). Some international evidence on output inflation tradeoffs. American Economic Review 63: 326-334.

McCallum, Bennett T., and Edward Nelson (2000). Timeless perspective vs. discretionary monetary policy in forward-looking models. NBER Working Paper No. 7915.

Milas, Costas, and Ruthira Naraidoo (2012). Financial conditions and nonlinearities in the European Central Bank (ECB) reaction function: In-sample and out-of-sample assessment. Computational Statistics and Data Analysis 56: 173-189.

Minford, Patrick, and David Peel (2002). Advanced macroeconomics: a primer. Cheltenham, UK: Edward Elgar Publishing Ltd.

Naraidoo, Ruthira, and Leroi Raputsoane (2011). Optimal monetary policy reaction function in a model with target zones and asymmetric preferences for South Africa. Economic Modelling 28: 251-258.

Naraidoo, Ruthira, and Ivan Paya (2012). Forecasting monetary policy rules in South Africa. International Journal of Forecasting 28: 446-445.

Naraidoo, Ruthira, and Leroi Raputsoane (2013). Financial markets and the response of monetary policy to uncertainty in South Africa. forthcoming.

Nobay, A. Robert, and David A. Peel Optimal discretionary monetary policy in a model of asymmetric central bank preferences. Economic Journal 113: 657-665.

Orphanides, Athanasios, Richard D. Porter, David Reifschneider, Robert Tetlow, and Fredrico Finan (2000). 
Errors in the measurement of the output gap and the design of monetary policy. Journal of Economics and Business 52: 117-141.

Orphanides, A., and David W. Wilcox (2002). The opportunistic approach to disinflation. International Finance 5: 47-71.

Peel, David. A. (2001). Uncertain central bankers preference: some implications of multiplicative versus additive uncertainty. Applied Economics Letters, Taylor \& Francis Journals 8: 17-20.

Roberts, John M. (2006). Monetary policy and inflation dynamics. International Journal of Central Banking 2: 193-230.

Rudd, Jeremy, and Karl Whelan (2005). New tests of the new-Keynesian Phillips curve. Journal of Monetary Economics 52: 1167-1181.

Rudebusch, Glen D. (2005). Assessing the Lucas critique in monetary policy models. Journal of Money, Credit, and Banking 37: 245-272.

Ruge-Murcia, Francisco F. (2003). Does the Barro-Gordon model explain the behavior of US inflation? A reexamination of the empirical evidence. Journal of Monetary Economics 50: 1375-1390.

Ruge-Murcia, Francisco F. (2004). The inflation bias when the central bank targets the natural rate of unemployment. European Economic Review 48: 91-107.

Söderström, Ulf (2002). Monetary policy with uncertain parameters. Scandinavian Journal of Economics 104: 125-145.

Surico, Paul (2007). The Fed's monetary policy rule and US inflation: the case of asymmetric preferences. Journal of Economic Dynamics and Control 31: 305-324.

Surico, Paul (2008). Measuring the time inconsistency of US monetary policy. Econometrica 75: 22-38.

Svensson, Lars E. O., and Noah Williams (2008). Optimal monetary policy under uncertainty: a Markov jumplinear-quadratic approach. Review, Federal Reserve Bank of St. Louis 90: 275-294.

Sweidan, Osama D. (2009). Asymmetric central bank's preference and inflation rate in Jordan. Studies in Economics and Finance 26: 232-245.

Tillman, Peter (2011). Parameter uncertainty and nonlinear monetary policy rules. Macroeconomic Dynamics 15: $184-200$.

Wieland, Voler (2000). Monetary policy, parameter uncertainty, and optimal learning. Journal of Monetary Economics 46: 199-228.

Woodford, Michael (1999). Optimal monetary policy inertia. Working Paper 7261, NBER. 